\title{
O que está acontecendo com a pesquisa sobre cidades mundiais?
}

\section{What's happening to world city research?}

Anthony D. King

Em 1982, John Friedmann e Goetz Wolff publicaram o agora famoso artigo World Cities: An Agenda for Research and Action ("Cidades mundiais: uma pauta para pesquisa e ação") no International Fournal of Urban and Regional Research. Desde então, a ideia de "cidade global" ou "cidade mundial" desenvolveu-se ainda mais e, investida de imensa sofisticação por Saskia Sassen, Peter Taylor e seus colegas na Loughborough University e por muitos outros, tornou-se totalmente integrada ao vocabulário conceitual de sociólogos, geógrafos e urbanistas em geral. Essa ideia dominou, ou pelo menos influenciou, a pesquisa de muitos outros. De forma ainda mais decisiva, norteou as pautas competitivas de grandes cidades e também das de porte médio. Encorajou megaprojetos

O presente artigo foi apresentado originalmente na conferência da International Network for Urban Research and Action - INURA, realizada em Zurique, Suíça, em 7 de junho de 2007.

Anthony D. King é professor emérito de Sociologia e História da Arte, na Binghamton University, estado de Nova York, Estados Unidos (adking@blueyonder.co.uk).

Artigo recebido em 23 de dezembro de 2008 e aprovado para publicação em 20 de agosto de 2010.

Est. Hist., Rio de Faneiro, vol. 23, $n^{o}$ 46, p. 247-260, julho-dezembro de 2010. 
ambiciosos, principalmente na Ásia, no intuito de manter, ou mais comumente, tentar adquirir este status místico de cidade "mundial" ou "global" (agora os dois rótulos são permutáveis).

A competição pelo status de "cidade mundial" não apenas exacerbou radicalmente a polarização espacial, social e econômica entre ricos e pobres em muitas cidades, mas em algumas cidades asiáticas (Délhi, por exemplo), forças políticas conservadoras nela encontraram respaldo para levar para longe dos olhos, se não das mentes, os assentamentos ilegais, as ocupações irregulares, as slums de toda ordem.

A ideia de Saskia Sassen de que essas cidades globais possuem "recursos para exercer um controle total" talvez seja a assertiva mais radical sobre essas formas urbanas. A definição oferecida pelo site Wikipédia (uma expressão da globalização em si mesmo) aponta igualmente para o poder que elas são capazes de exercer: "cidade global é uma entidade cujos vínculos de integração refletem-se de forma direta e exequível nas questões mundiais".

Os critérios usados em 1986 por Friedmann para determinar o status de cidade mundial como "centros de controle e comando" da economia do planeta eram relativamente modestos: números de bancos internacionais, sedes de empresas transnacionais, instituições internacionais com diferentes fins, número crescente de centros comerciais e financeiros, redes de transporte avançadas etc. A lista inicial de Friedmann reunia 30 e tantas cidades. Subsequentemente, como os critérios para seleção tornaram-se mais sofisticados, outros estudiosos, como Peter Taylor, elevaram esse número para cerca de 80 . O status relativo das cidades mundiais passou a ser julgado de acordo com sua provisão de serviços ditos avançados ou pertinentes ao setor terciário: contabilidade, publicidade, finanças, leis, serviços de consultoria e finanças oferecidos por multinacionais.

Segundo esses critérios, ainda de acordo com o site Wikipédia, as cidades mundiais foram agrupadas em uma hierarquia de 124 cidades ao redor do globo. No topo, as "cidades mundiais full service", aí incluídas Londres, Paris, Nova York e Tóquio; em seguida, as "cidades mundiais de grande porte", como Zurique, San Francisco, Sydney e Toronto; depois, as "cidades mundiais de porte médio", e assim por diante. No final da lista da Wikipédia ficaram as cidades que, para usar a expressão de Friedman, revelam "forte potencial para cidade mundial”, como Adelaide, na Austrália, e Wellington, na Nova Zelândia.

Imagino que essa lista de desempenho seja do interesse de banqueiros, administradores de cidades e de alguns setores da economia, mas devo admitir que, desde que publiquei meu livro sobre Londres como cidade global, há 20 anos, meu interesse sobre o tema diminuiu um pouco. Isso se deve a dois ou três motivos que gostaria de discutir aqui. 
O primeiro é a sua natureza ahistórica. Pelo que eu saiba, com uma ou duas exceções, ninguém tentou mostrar, historicamente, porque e como estas cidades mundiais tão famosas atingiram o status de cidade mundial no presente seja em relação a outras cidades no mesmo país, seja, principalmente, em relação a cidades em outros países. O que me interessa saber - digamos, sobre Zurique ou Londres - não é tanto o que têm em comum, mas sim como suas trajetórias históricas e culturais se refletem na sua organização como cidade mundial.

Segundo, o foco de cunho economicista que informa grande parte da pesquisa sobre cidade mundial há 25 anos (particularmente a obsessão com o fornecimento de serviços do setor terciário). Creio que este foco comprometeu o exame de outras mudanças significativas no mundo, sejam elas políticas, culturais ou sociais. A pesquisa sobre cidades mundiais dirigiu-se quase exclusivamente para as cidades da economia mundial, negligenciando a complexidade de sistemas políticos e culturas concorrentes, muitas vezes hostis e intrinsecamente diferentes. $\mathrm{Na}$ minha visão, as diferenças nas condições globais que afetaram e continuam a afetar as cidades mundiais são tão importantes, se não mais, quanto a suposta semelhança entre elas. Nesse sentido, proponho-me a discutir aqui as condições culturais distintivas que afetaram não apenas Londres, mas a situação urbana da Grã-Bretanha à qual Londres está intrinsecamente ligada. Para aqueles que estão familiarizados com meus trabalhos anteriores, não vai haver nenhuma surpresa em saber que começo me referindo às condições do imperialismo, do pós-imperialismo e da pós-colonização.

\section{O imperialismo e o sistema de cidade mundial}

Uma olhada em qualquer bom atlas de 1900, quando o mundo era dominado por 16 grandes impérios europeus e asiáticos, mostra que a maioria, senão todas, das 80 e tantas cidades citadas por Peter Taylor em sua pesquisa sobre cidades mundiais (Taylor 2004: 40-41), eram, na época (e anteriormente), capitais ou grandes cidades dos impérios europeus e asiáticos ou, ainda, cidades estabelecidas por estes impérios em seus territórios coloniais. (Aqui, trato as "cidades mundiais" das Américas do Sul e do Norte, África do Sul, Ásia, além da Austrália, como, essencialmente, resultado da expansão colonial europeia e asiática e, quando vistas do ponto de vista da população local, são colonizadoras ou imperiais). Deixe-me começar com alguns fatos bastante simples.

Em 1787 Goethe usou o termo weldstadt, "cidade global” em alemão, para se referir a Roma e depois Paris, cidades que ele pensava ter uma "eminência cultural" particular. Em 1966, Peter Hall usou o mesmo termo, em inglês, 
para se referir àquelas cidades para onde "grande parte dos negócios mundiais eram dirigidos". O primeiro uso do termo "cidade global" como título de livro data de 1969. A obra, escrita pelo historiador americano Theodore von Laue, descrevia a metrópole ocidental que cria confluência global, conceito que atualmente identificamos como globalização. Portanto, o termo em si e o que ele descreve têm uma longa história.

Hoje, na literatura das cidades mundiais, a importância das redes criadas por comunicações telemáticas, de tecnologia da informação, satélites e wireless é essencial. Porém, este sistema de rede se apoia em alicerces muito mais básicos. Em 1900, as redes ligando estas cidades ao centro metropolitano - fosse por mar, por terra, ou eventualmente pelo ar - eram efetuadas por telégrafo, telefone, imprensa, correio e pelos processos econômicos e sociais de migração. Estavam sincronizadas mais poderosamente através de várias instituições coloniais e imperiais - econômicas, sociais, políticas e culturais, adaptadas e transformadas em vários graus através da interferência autóctone e local. Dessas instituições, vamos examinar primeiro a importantíssima questão da língua.

As seis línguas oficiais das Nações Unidas são aquelas que historicamente pertenceram aos maiores impérios do mundo (britânico, russo, espanhol, árabe, Qing chinês e francês). Além disso, como Walter Mignolo destacou, 75\% da população do mundo falam 12 línguas, das quais seis - inglês, espanhol, alemão, português, francês e italiano - são aquelas das principais potências imperiais europeias e americanas. Tudo isso constitui explanação suficiente sobre a importância passada e contínua dos impérios de outrora e de suas principais cidades em disseminar suas línguas, formas de lei e governo, religiões e culturas.

Outras redes poderosas foram sustentadas pelas instituições formais de sistemas específicos de crenças (catolicismo na América do Sul e alhures; variações do protestantismo). Essas influências foram significativas em alguns locais, e embora tenham sido menos poderosas em outras sociedades mais secularizadas, mesmo assim sedimentaram valores. As redes mais antigas do islamismo, antes da hegemonia europeia, eram igualmente poderosas no mundo asiático e no Oriente Médio, e eram conhecidas por se basearem em conceitos radicalmente diferentes de tempo e espaço. $\mathrm{O}$ mesmo pode ser dito em relação à cosmologia do hinduísmo, do budismo e de outros sistemas de crenças.

Ainda a respeito da língua. Acompanhando a hegemonia europeia, desde o seu começo no século XVI, as redes lusofônicas, hispanofônicas, francofônicas e anglofônicas, transformadas por identidades locais, continuam hoje a fornecer a base para a comunicação transnacional na vida comercial e pública. Devemos também tomar nota dos regimes de conhecimento estabelecidos através dessas línguas, tanto na metrópole da época quanto nas suas colônias, e prin- 
cipalmente os resultantes da expansão da esfera cultural euro-americana anglofônica (ou seja, a hegemonia dos Estados Unidos). Esses regimes de conhecimento são responsáveis primeiramente pelo fato de que, no que se refere a muitas áreas do saber, o que é frequentemente referido como conhecimento "internacional” (Gutierrez e Lopez-Nieva, 2001) é, de fato, pós-colonial (King, 2004). De que outra forma explicar por que a língua da academia é hoje o inglês ("internacional") e não o árabe, o mandarim ou o hindu?

Se a questão da língua é um aspecto cultural muito, se não completamente, ignorado na pesquisa de cidade mundial, a outra é a religião. Foram necessários os acontecimentos de 11 de setembro de 2001 para nos lembrar que a grande maioria destas 80 e tantas cidades mundiais estavam em territórios que fazem parte, historicamente, do ecúmeno judeu-cristão. (Na Europa, partidos políticos ainda se autoidentificam como "democratas cristãos" e nas Américas, a religião, principalmente o fundamentalismo cristão evangélico, é um fator significativo na política). Onde este não é o caso - como Mumbai, Jacarta, Hong-Kong ou Kuala-Lumpur -, podemos de todo modo perguntar se suas credenciais emergentes de cidade mundial se apoiam em instituições e práticas desenvolvidas no seu passado colonial. Já Cairo (outra das 82 "cidades mundiais" mencionadas acima) foi descrita como a "(cidade) mãe do mundo", "a glória do islamismo e o centro do comércio mundial" no longínquo século $\mathrm{X}$, bem antes da época da hegemonia europeia (Abu-Lughod, 1989:149, 225).

Em resumo, a pesquisa sobre cidades mundiais/globais com foco cultural e histórico pode fornecer uma resposta a uma das perguntas ainda não respondidas na pesquisa de "cidade mundial/global": por que tantas cidades importantes no mundo não são, de acordo com os critérios atualmente usados para identificá-las, "cidades mundiais/globais" (King, 2000)?

A partir de meados do século XX, com o fim dos impérios europeus e asiáticos, tornou-se comum falar dos espaços pós-imperiais ou pós-coloniais que eles deixaram para trás. $\mathrm{O}$ argumento do meu livro sobre como Londres tornou-se uma cidade global é resumido no seu título e, principalmente, no seu subtítulo: Global Cities: Post-Imperialism and the Internationalization of London (Cidades globais: o pós-imperialismo e a internacionalização de Londres). Em síntese, ali argumento que praticamente toda a infraestrutura e também o capital e a capacidade de aumentá-lo já estavam presentes na capital imperial no início do século XX, muito antes de ser renomeada como "cidade global" com "capacidade de controle global", para usar o termo cunhado por Saskia Sassen. A "internacionalização" integral de Londres ocorreu a partir da década de 1950, após o fim do império.

Permitam-me, agora, dizer algo sobre a importância dessas redes póscoloniais tão distintas - em termos de etnia, língua, religião e cultura -, que in- 


\section{Anthony D. King}

fluenciam as operações, não apenas da "cidade global" de Londres, mas também de outras importantes áreas urbanas da Grã-Bretanha, regiões intrinsecamente ligadas à cultura, economia e política da capital.

\section{Cidade pós-imperial}

Uma das características frequentemente citadas da cidade global ou mundial é o cosmopolitismo de sua população. As cidades mundiais, afirma-se, são cidades essencialmente internacionalizadas, contando com residentes do mundo todo. Mas de onde eles vêm, que proporção representam em termos populacionais e qual sua relevância na cidade?

$\mathrm{Na}$ Grã-Bretanha, quase metade das minorias étnicas do país (o equivalente a cerca de $9 \%$ da população total) mora em Londres, onde representa nada menos que $1 / 5$ da população da cidade. De longe, a maior parte desta população pode ser descrita, dependendo da nossa perspectiva, como pós-colonial (ou seja, tendo origens nas colônias da época) ou pós-imperial (uso este termo em um sentido técnico e não político, e não somente em relação à presença do Reino Unido no Iraque, ou seja, "estamos aqui porque vocês estavam lá"). A importância da categoria pós-colonial em uma discussão de cidades mundiais e globalização é enorme. Por que? Por vários motivos.

Os povos pós-coloniais possuem uma relação diferente com a sociedade anfitriã. Em escala maior ou menor, eles estão familiarizados com a língua, as instituições, a cultura; estão também cientes, em graus variáveis, das históricas ligações coloniais (algumas negativas, algumas positivas) com a metrópole de outrora. Como todos os migrantes, também possuem ligações e redes que remetem a seus países de origem, mas ao contrário de outros migrantes, suas redes se estendem para outros locais pós-coloniais - no caso de asiáticos britânicos, por exemplo, não raro possuem parentes no Canadá, Austrália, Estados Unidos, no Golfo Persa, Cingapura etc.

A minoria étnica de maior expressão numérica na Grã-Bretanha é a que vem do sul da Ásia, predominantemente Índia, mas também do Paquistão, Bangladesh e Sri Lanka. Seu contingente passou de $100 \mathrm{mil} \mathrm{em} 1950$ para cerca de 2,8 milhões em 2004 (Peach, 2005), e encontra-se distribuído entre Londres, a porção centro-ocidental (Birmingham e Leicester) e as decadentes cidades produtoras de tecidos do norte, as antigas "áreas têxteis" de Lancashire e Yorkshire ocidental. Como no caso da população afro-caribenha presente nas ex-metrópoles da Europa, os asiáticos britânicos podem ser tomados como a razão de se falar em uma "Grã-Bretanha multicultural” (termo, aliás, cada vez mais contestado), 
como abordado em uma coleção recente de ensaios, $A$ Postcolonial People: South Asians in Britain [Um povo pós-colonial: sul-asiáticos na Grã-Bretanha] (Ali, Kalra e Sayyid, 2005). Vale lembrar que na Grã-Bretanha, o Serviço Nacional de Saúde depende extensivamente de enfermeiras e médicos migrantes de segunda geração de origem sul-asiática.

Outros importantes setores profissionais, do universitário ao farmacêutico, também são dominados por pessoas do sul da Ásia. Um estudo recente sobre os 200 asiáticos mais ricos da Grã-Bretanha sugere que a fortuna deste grupo cresceu três vezes mais rápido do que a economia em geral. Os setores mais antigos da economia - desenvolvidos há duas ou três décadas por empresários asiáticos, como produtos têxteis, indústria e supermercados - foram firmemente abandonados em favor do setor de serviços e de indústrias high-tech, aqui incluídos, sobretudo, produtos farmacêuticos, telefones sem fio e hotéis (Guardian, 4 de setembro de 2006). O homem mais rico no país é Lakshmi Mittal, o magnata global do aço indiano. Os Hinduja Brothers, industriais que ocupam o segundo lugar na lista, fizeram grandes contribuições à Universidade de Cambridge para encorajar pesquisas sobre o hinduísmo antigo. Há pouco tempo, o capitão do time inglês de críquete era um descendente de indianos (um dos principais jogadores atuais do time também o é).

Os migrantes sul-asiáticos destacam-se ainda na grande imprensa, nas artes e na literatura inglesa contemporânea (com vários prêmios acumulados). A presença pós-colonial do sul da Ásia na sociedade britânica é, portanto, muito significativa. Por meio de ligações com a Ásia meridional e com diferentes setores da economia global, eles exercem grande impacto, não apenas na cidade global de Londres, como também na economia e sociedade britânicas como um todo. É dessa forma que a história de qualquer cidade global é bastante singular. Sua história não apenas a torna diferente das de outras - o que devo chamar aqui de "diferença pós-colonial" -, mas também possui a capacidade de transformar profundamente a maneira pela qual funciona. Permitam-me dar três exemplos.

\section{Diferença pós-colonial}

O primeiro é uma ilustração relativamente pequena, mas útil, de como a política de identidade local impacta o cenário global. No verão de 2005 , quando a British Airways (e outras linhas aéreas) tentava a todo custo permanecer economicamente viável, a Gate Gourmet, uma firma de serviço de bufê - responsável pelas refeições embaladas servidas nos voos da British Airways, e de propriedade de uma firma americana de capital de risco, com base na Suíça - cortou mais de 


\section{Anthony D. King}

600 empregos para reduzir seus custos operacionais. Entretanto, suas desastrosas relações trabalhistas - não houve praticamente nenhum aviso ou compensação aos trabalhadores demitidos - levaram a uma greve imediata da mãode-obra. Os grevistas eram, em sua grande maioria, mulheres indianas punjabi, que recebiam baixos salários e trabalhavam onde as firmas prestadoras de serviços ao aeroporto são praticamente os únicos empregadores.

Heathrow se localiza muito próximo a Southall, uma das maiores e mais antigas áreas de concentração de indianos punjabi na Grã-Bretanha. Eles representam cerca de $40 \%$ da população do município. A greve dos trabalhadores de fornecimento foi imediatamente seguida por uma greve de carregadores de bagagem e trabalhadores de carga. Estes também eram, em sua maioria, indianos punjabi, que se solidarizaram com seus colegas, em muitos casos esposas, irmãs, mães e primas, que faziam o fornecimento de comes e bebes. Embora o sucesso da greve possa remeter ao apoio de um grande sindicato ( $T$ and $G$ ), o movimento que fechou a British Airways durante dias e custou cerca de $£ 10$ milhões por dia tornou-se sobretudo uma mostra da solidariedade e da força da identidade punjabi e da comunidade indiana local (mais do que "simplesmente" do apoio do sindicato). A empresa foi obrigada a ceder.

Ainda como essa história de uma comunidade predominantemente punjabi sikh mostra, o termo sul asiático pode ser enganoso. Afinal, não consegue dar conta das diferenças étnicas, econômicas, sociais e religiosas entre pessoas de ascendência indiana na Grã-Bretanha. Tal termo também ignora a extensão da concentração geográfica e o acesso altamente desigual que cada subgrupo (paquistaneses, sikhs etc.) tem em relação às oportunidades de educação e emprego. Os paquistaneses, por exemplo, que migraram para Bradford (Yorkshire, no norte da Inglaterra) na década de 1960 eram, em sua maioria, agricultores analfabetos e não qualificados do distrito de Mirpur da Caxemira Livre, e isso foi essencial para influenciar a cultura subsequente. Isso me leva ao segundo exemplo do que estou chamando de "diferença pós-colonial" na cidade global.

A etnia paquistanesa é, obviamente, reforçada pela religião, já que a imensa maioria dos paquistaneses é muçulmana (esta e as informações seguintes são de McLoughlin, 2005). A presença dessa população britânica muçulmana é visível sobretudo em locais como Bradford (cerca de $320 \mathrm{~km}$ de Londres) onde, em 2001, havia 75.188 muçulmanos comparados com menos de 5 mil sikhs e o mesmo número de hindus. Hoje os paquistaneses representam $15 \%$ da população total da cidade, e estão amplamente segregados em áreas específicas. Das 288 escolas de ensino médio da região, dez possuem $90 \%$ ou mais de alunos oriundos de um desses subgrupos (Observer, 27 de maio de 2007). Bradford é próxima de Leeds, onde a proporção novamente muda: embora a cidade tenha ficado famosa 
como residência de três dos islâmicos radicais (também cidadãos do Reino Unido) que bombardearam Londres em 7 de julho de 2005 (e a quem retorno em breve), ali a porcentagem mais alta é de indianos (hindus).

No norte da Inglaterra, na fronteira de Yorkshire, em Lancashire, está Blackburn with Darwen, um aglomerado urbano com cerca de 137 mil habitantes, onde a população paquistanesa (na maioria muçulmana) representa $27 \%$ do total. Em um recente documentário de 30 minutos da $\mathrm{BBC}$ sobre as relações da comunidade em Blackburn (Panorama BBC, $1^{\circ}$ de abril de 2007), o programa retratou, com base em relatos não apenas de moradores, mas também de funcionários do governo, uma situação de quase $100 \%$ de segregação social, cultural, religiosa e espacial entre a população branca e a muçulmana paquistanesa. Além de frequentarem escolas completamente diferentes (algumas com $95 \%$ de brancos ou $95 \%$ de paquistaneses), os jovens movimentavam-se por partes completamente diferentes da cidade e cultuavam em locais totalmente separados, sem que houvesse praticamente qualquer contato diário entre eles. Como resposta à crítica feita pelo ex-primeiro-ministro e ex-secretário do Exterior, Jack Straw, ao véu e à burca das muçulmanas, cresceu visivelmente o número de mulheres que agora se vestem desta maneira. A situação foi resumida, no documentário, como a de duas comunidades vivendo "vidas paralelas" e separadas.

De acordo com o comentário de um consultor acadêmico, não foi só uma questão de racismo ou cor da pele, e sim uma combinação mais complexa de raça, religião, língua e cultura. Chamou-se a atenção, ainda, para o fato de que alguns experimentos preliminares de misturar crianças de diferentes etnias nas escolas teve como efeito perverso o chamado white flight [retirada das populações brancas dos bairros ocupados por minorias étnicas]. Por causa da história de ambas as comunidades, branca e paquistanesa, e a contínua divisão "norte-sul” na GrãBretanha (o norte pós-industrial mais pobre contrastando com o sul mais próspero), a situação econômica das cidades do norte continua reproduzindo uma divisão de classes semelhante entre a comunidade branca e a segunda geração asiática. Tanto asiáticos quanto brancos são predominantemente da classe operária. E por causa dos aspectos segregados de suas vidas, da falta de oportunidade de emprego e da pobreza, muitos dos idosos e mulheres da comunidade paquistanesa não têm acesso ao inglês.

Um relatório de 2002 sobre Bradford, elaborado após as desordens raciais nas cidades de Lancashire do ano anterior, reflete de maneira precisa a situação, não apenas em Bradford, mas também em Blackburn e outros locais vizinhos. Havia evidências de desconfiança crescente e polarização de comunidades muçulmanas e não-muçulmanas, de um rápido aumento no número de jovens muçulmanos descontentes, do surgimento de práticas de auto-exclusão, do fra- 
casso de líderes religiosos tradicionais em se conectar ao mundo da juventude muçulmana britânica e do impacto cumulativo de tais questões no desempenho educacional. Bradford era considerada "sob o poder do medo", incapaz de falar honesta e abertamente sobre os problemas das comunidades e entre as comunidades: medo de ser racista, medo de confrontar uma cultura de gangue e comércio de drogas ilegais (Lewis, citado em McLoughlin, 2005:134). Essas condições sociais e econômicas, que afetavam o que o autor chama de "juventude muçulmana descontente", foram essenciais na transformação de algumas identidades asiático-britânicas, um processo que, para alguns, foi exacerbado pelo desastroso ataque britânico ao Iraque, liderado pelos Estados Unidos, bem como pelos alertas de segurança e pelas buscas policiais que se seguiram e que associavam mulçumanos a "terroristas".

Em um ensaio sobre as transformações estruturais por que as identidades muçulmanas pós-coloniais têm passado na Grã-Bretanha, Shehla Khan (2005) demonstra que a criação de uma identidade de registro islâmico marcou o surgimento de um novo tipo de política que já não encontra sua referência nas "relações de raça" tradicionalmente previstas pelo Estado. Em vez disso, os jovens muçulmanos britânicos se auto-identificam cada vez mais a partir de uma posição "transétnica", que não pode ser contida dentro das categorias étnicas, raciais ou sociais estabelecidas há décadas pelo Estado britânico. Dito de outro modo, as novas identidades muçulmanas britânicas foram fragmentadas e romperam a taxonomia social e racial previamente usada pelo Estado para organizar e disciplinar suas populações étnicas. Khan argumenta que a identificação crescente dos jovens paquistaneses britânicos com uma subjetividade muçulmana separa-os da ideia prévia de "asianidade britânica" [British Asianness] e, no processo, enfraquece-a como identidade de fato válida. "Asianidade britânica" passa a ser uma identidade associada apenas a motivos essencialmente indianos (em vez de especificamente muçulmanos), como Bollywood e a música Bhangra, típica dos sikhs punjabi.

Essas conjunturas específicas ajudam a explicar a existência dos quatro extremistas islâmicos, aos quais me referi acima, vivendo nos bairros operários de Leeds e da vizinha Dewsbury. Foram justamente jovens muçulmanos britânicos, cujas subjetividades pós-coloniais foram radicalizadas em campos de treinamento no Paquistão, que se tornaram os "bombardeadores de Londres de 7/7" -7 de julho de 2005, matando 52 vítimas inocentes, ferindo centenas de outras, no metrô e em um ônibus de Londres. Sob o ponto de vista deles, seu feito tornava-os mártires islâmicos. Como argumenta Khan, trata-se "do caráter fluido" intrínseco à natureza global da identidade muçulmana.

É aí que a ideia de uma Londres contida por fronteiras nacionais - poderíamos falar de Madri ou de qualquer outra assim chamada "cidade mundial" - 
começa a perder força. Hoje, tipos muitos diferentes de sujeitos estão se posicionando e agindo dentro de um quadro global de referência, independente de onde eles vivem. Não são apenas os banqueiros e corretores das bolsas de valores que vivem nas "cidades globais" de renome, mas também a população socialmente marginalizada e politicamente ativa de Yorkshire.

Enquanto Nova York, Madri ou Londres tornam-se os locais preferidos do terror, as condições que produzem este terror não se estendem meramente a cidades a $320 \mathrm{~km}$ de distância, como no caso exemplificado acima, mas também aos locais em que novas identidades globais são forjadas. No caso dos jovens bombardeadores, estas identidades movimentaram-se entre Leeds e Lahore, no Paquistão, dando quase meia volta ao redor do mundo. Em 2005, de acordo com o chefe da Divisão de Segurança da Polícia Metropolitana, foram feitas cerca de 400 mil viagens de ida e volta ao Paquistão por paquistaneses britânicos residentes na Grã-Bretanha. Praticamente a totalidade dessas viagens foi feita sem qualquer conexão com o terror, motivadas apenas por laços familiares e arranjos maritais e, sobretudo, pela necessidade de prestar assistência monetária e emocional aos parentes (é preciso lembrar aqui do desastroso terremoto ocorrido no $\mathrm{Pa}$ quistão em 2004).

Ainda de acordo com a Polícia Metropolitana, cerca de dois mil indivíduos encontram-se atualmente sob vigilância. Os custos econômicos desta vigilância (sem mencionar os custos sociais, psicológicos e humanos, principalmente para os membros da comunidade muçulmana que são crescentemente demonizados por ações desse tipo) são calculados em $£ 1$ bilhão por ano, a serem duplicados nos próximos anos. Cerca de $£ 800$ milhões, aproximadamente $1 / 12$ do orçamento de $£ 9,5$ bilhões propostos para os Jogos Olímpicos de 2012, serão gastos com segurança. Esse dinheiro teria melhor destino se fosse gasto no atendimento das urgentes necessidades de moradia, educação, emprego e bem-estar das próprias comunidades, seja no norte da Inglaterra seja na comunidade bengalesa do leste de Londres (isso sem falarmos do quanto estas ações policiais contribuem para a criação de um pânico moral).

Deixem-me passar, por fim, ao terceiro e último exemplo da importância do que chamei de "diferença pós-colonial" ou "excepcionalismo pós-colonial" para a compreensão da cidade mundial.

Nos últimos dez anos, houve um crescimento enorme do número de vagas de emprego no setor das tecnologias de comunicações e informação para atender a diferentes partes do antigo império anglofônico, especificamente Estados Unidos, Canadá, Reino Unido e Índia. Para darmos apenas um exemplo, a expansão dos call centers na Índia criou mais de 100 mil novos empregos, gerando um negócio da ordem de de $\$ 1,4$ bilhões (King 2004:152). Trata-se de uma atividade ba- 


\section{Anthony D. King}

seada na existência de uma população altamente articulada, fluente em inglês e educada em um sistema universitário indiano cada vez mais voltado para o Ocidente a quem são oferecidos subempregos que remetem à velha ordem colonial.

Raramente é reconhecido, se alguma vez o é, que, depois dos Estados Unidos, a Índia possui a maior população fluente em inglês no mundo. (É interessante aqui comparar a Índia onde, desde a independência em 1947, o aprendizado do inglês passou a dominar as aspirações de todos os indianos emergentes, com a Indonésia, onde o ensino do inglês nas escolas foi abandonado por motivos nacionalistas, reduzindo maciçamente a proporção de indonésios nas instituições ocidentais de ensino superior). $\mathrm{O}$ desenvolvimento do call center, setor baseado em tecnologia e fluência no idioma, não apenas criou extensas oportunidades de emprego na Índia, mas também gerou um sólido boom de construção civil nos subúrbios de cidades como Délhi, Bangalore e Hyderabad (King, 2004).

\section{Conclusão}

Espero ter mostrado que meu argumento sobre as origens coloniais e imperiais de muitas cidades mundiais ou globais de renome não é somente uma questão de "acabar com os mal-entendidos". Meu objetivo foi chamar a atenção para a natureza excessivamente economicista dos critérios que informaram até aqui o "paradigma de cidade mundial", cujo resultado foi um enquadramento teórico bastante limitado. Também me parece fundamental destacar o fato da $d i$ ferença, principalmente da diferença pós-colonial, na "cidade global". Como outros apontaram, carecem de fundamento sério as suposições de que o "urbanismo global pode ser considerado como um crescimento uniforme ou homogêneo da Europa e da América, que afeta tardiamente a África, Ásia e América do Sul" ou que "cidades na África, Ásia ou América do Sul podem ser entendidas no modelo de cidades da Europa, Austrália ou dos EUA" (Bishop et al, 2003:2).

É preciso que, além da prática, as pesquisa, ao tomarem o fenômeno da globalização como objeto, tratem também dos temas da pobreza, da exclusão social e do desemprego que impactam não apenas as oportunidades e identidades das minorias étnicas em cidades-mundiais no Ocidente, mas também ajudam a reproduzir iniquidades mundo afora.

Dado que há uma previsão de que as minorias étnicas de Londres, e sem dúvida de muitas outras cidades na Grã-Bretanha (assim como Toronto, no Canadá, e Los Angeles, nos Estados Unidos), serão maioria nos próximos 15 anos, estes são problemas vitais a combater. Com efeito, estima-se que em 2012, Birmingham será a primeira cidade de minoria-maioria do Reino Unido. Em outubro de 2006, $40 \%$ dos jovens londrinos entre 16 e 24 anos pertenciam a minorias étnicas. 
Referências bibliográficas

ABU-LUGHOD, Janet. Before European Hegemony: The World System A. D. 1250-1350. Nova York: Oxford University Press, 1989.

ALI, Nasren; KALRA, Virinder S. \& SAYYID, Salman (eds). A Postcolonial People: South Asians in Britain. Londres: Hurst and Co., 2005.

BISHOP, Ryan; PHILLIPS, J. \& YEO. W. W. (eds.) Postcolonial Urbanism: South Asian Cities and Globalization. Londres e Nova York: Routledge, 2003.

CHAKRABARTY, Dipesh. Provincialising Europe: Postcolonial Thought and Historical Difference. Princeton, NJ: Princeton University Press, 2000.

HARGREAVES, Alec G. \& McKINNEY, Mark. Postcolonial Cultures in France. Londres e Nova York: Routledge, 1997.

HOPKINS, Antony G. (ed.). Globalization in World History. Londres: Pimlico, 2001.

KHAN, Shehla. Muslims! In: ALI, Nasren; KALRA, Virinder S. \& SAYYID, Salman (eds.), op.cit., p. 182-187.

KING, Anthony D. Global Cities: PostImperialism and the Internationalization of London. Londres e Nova York: Routledge, 1990.

Postcolonialism, Representation, and the City. In: BRIDGE, Gary \& WATSON, Sophie (eds.). A Companion to the City. Oxford: Blackwell Publishers, 2000, p. 261-269.
- Spaces of Global Cultures: Architecture, Urbanism, Identity. Londres e Nova York: Routledge, 2004.

KNOX Paul L. \& TAYLOR, Peter J. (eds.). World Cities in a World-System. Cambridge: Cambridge University Press, 1995.

McLOUGHLINM, Sean. Writing a BrAsian City: "Race," Culture and Religion in Accounts of Postcolonial Bradford. In: ALI, Nasren; KALRA, Virinder S. \& SAYYID, Salman (eds.), op. cit.., p. 110-140.

MERRIMAN, Nick (ed.). The Peopling of London: Fifteen Thousand Years of Settlement from Overseas. Londres: $\mathrm{Mu}-$ seum of London, 1993.

NASSER, Noha. The Space of Displacement: Making Muslim South Asian Place in British Neighborhoods. Traditional Dwellings and Settlements Review, 15, 1:7-21, 2003.

PEACH, Cari. Demographics of BrAsian Settlement,1951-2001. In: ALI, Nasren; KALRA, Virinder S. \& SAYYID, Salman (eds.), op. cit., p. 168-181.

SASSEN, Saskia. The Global City: New York, London, Tokyo. Princeton: Princeton University Press, 2001.

TAYLOR, Peter J. World City Network: $A$ Global Urban Analysis. Londres e Nova York: Routledge, 2004.

Zurich as a World City, 2005 (mimeo.) 


\section{Resumo}

A pesquisa sobre cidades mundiais, que dominou os anos 1990, tratou mais das cidades e menos do mundo. Invertendo essa ordem, este artigo indaga até que ponto o "paradigma das cidades-mundo" ainda pode ser considerado válido. Em vez de focar nos critérios econômicos e relativos ao mundo dos negócios, ou no desenvolvimento da cidade-mundo, o artigo detém-se nos fatores históricos e culturais. Tomando Londres como exemplo, demonstra como históricas conexões pós-coloniais com a Índia continuam a influenciar os destinos da cidade contemporânea.

Palavras-chave: paradigma das cidades-mundo; cidade global; pós-colonialismo; imperialismo; urbano.

\section{Abstract}

Research on world cities, dominating the 1990s, was more about cities, less about the world. Reversing that order, this paper asks to what extent the "world city paradigm" still has validity today. Rather than focusing on economic and business-related criteria in examining and assessing world city development (as is frequently the norm), the paper looks particularly at historical and cultural factors. Using the example of London, it shows how historical postcolonial connections with India continue to influence the everyday fortune of the contemporary city.

Key words: world city paradigm; global city; post-colonialism; imperialism; urban.

\section{Résumé}

La recherche sur les villes mondiales dominante aux années 1990 s'occupait plutôt des villes que du monde. En reversant cet ordre, l'auteur se demande à quel point le "paradigme des villes mondiales" peut encore être consideré valide. Au lieu de se concentrer sur les critères économiques et liés au monde des affaires, ou bien sur le dévélopement de la ville mondiale, l'article se penche sur des facteurs historiques et culturaux. En prennant Londres comme exemple, il demontre comment des liens historiques post-coloniaux avec l'Inde continuent à influencer le sort de la ville contemporaine.

Mots-clés: paradigme des villes mondiales; ville globale; post-colonialisme; imperialisme; urbain. 